\title{
Mapping migratory flyways in Asia using dynamic Brownian bridge movement models
}

Eric C Palm', Scott H Newman², Diann J Prosser ${ }^{1 *}$, Xiangming Xiao ${ }^{3,4}$, Luo Ze $^{5}$, Nyambayar Batbayar ${ }^{6}$, Sivananinthaperumal Balachandran ${ }^{7}$ and John Y Takekawa ${ }^{8,9}$

\begin{abstract}
Background: Identifying movement routes and stopover sites is necessary for developing effective management and conservation strategies for migratory animals. In the case of migratory birds, a collection of migration routes, known as a flyway, is often hundreds to thousands of kilometers long and can extend across political boundaries. Flyways encompass the entire geographic range between the breeding and non-breeding areas of a population, species, or a group of species, and they provide spatial frameworks for management and conservation across international borders. Existing flyway maps are largely qualitative accounts based on band returns and survey data rather than observed movement routes. In this study, we use satellite and GPS telemetry data and dynamic Brownian bridge movement models to build upon existing maps and describe waterfowl space use probabilistically in the Central Asian and East Asian-Australasian Flyways.

Results: Our approach provided new information on migratory routes that was not easily attainable with existing methods to describe flyways. Utilization distributions from dynamic Brownian bridge movement models identified key staging and stopover sites, migration corridors and general flyway outlines in the Central Asian and East Asian-Australasian Flyways. A map of space use from ruddy shelducks depicted two separate movement corridors within the Central Asian Flyway, likely representing two distinct populations that show relatively strong connectivity between breeding and wintering areas. Bar-headed geese marked at seven locations in the Central Asian Flyway showed heaviest use at several stopover sites in the same general region of high-elevation lakes along the eastern Qinghai-Tibetan Plateau. Our analysis of data from multiple Anatidae species marked at sites throughout Asia highlighted major movement corridors across species and confirmed that the Central Asian and East Asian-Australasian Flyways were spatially distinct.

Conclusions: The dynamic Brownian bridge movement model improves our understanding of flyways by estimating relative use of regions in the flyway while providing detailed, quantitative information on migration timing and population connectivity including uncertainty between locations. This model effectively quantifies the relative importance of different migration corridors and stopover sites and may help prioritize specific areas in flyways for conservation of waterbird populations.
\end{abstract}

Keywords: Dynamic Brownian bridge movement model, Flyways, Waterfowl, Migration, Stopover sites, Space use, Habitat conservation

\footnotetext{
* Correspondence: dprosser@usgs.gov

${ }^{1}$ U.S. Geological Survey, Patuxent Wildlife Research Center, Beltsville, MD

20705, USA

Full list of author information is available at the end of the article
} 


\section{Background}

For migratory animals, identifying movement routes and stopover sites is necessary for effective population management and habitat conservation [1,2]. Animals experience a variety of challenges during migration, including adverse weather, unpredictable food availability and geographic barriers such as mountain ranges, deserts and oceans. Some migratory birds spend over half of their annual cycle traveling between breeding and wintering areas, and challenges during these periods contribute to a substantial portion of annual mortality in many species [3-6]. However, there are disproportionately few studies analyzing space use during migration (e.g., $[7,8]$ ) relative to those that quantify space use during breeding and wintering periods (e.g., $[9,10]$ ).

A collection of avian migration routes, known as a flyway, is often hundreds to thousands of kilometers long and can extend across international borders. A flyway encompasses the entire geographic range between breeding and non-breeding areas of populations, single species or across multiple species, and provides a spatial framework for management and conservation across political boundaries [11]. Waterfowl migration routes are perhaps the best described flyways due to a long history of research and management. The concept of multi-species waterfowl flyways began in North America in the 1930s but has since spread to all major global flyways [12]. In 1935, Lincoln [13] first defined and mapped North American waterfowl flyways based entirely on band return data. These biological flyways formed the basis of administrative flyways in the United States, which were designed to manage populations and set hunting regulations [14]. Through the years, waterfowl flyway management programs in North America have become a unique example of long-term collaboration between wildlife research and management. Outside of the United States and Canada, organized flyway-level efforts to conserve waterbirds began in the 1960s in Eurasia and northern Africa, and the first waterbird flyway maps of western Eurasia were published in 1967 [15,11].

Organized research and flyway-level conservation initiatives in the Asia-Pacific region began much later, and even today, these flyways are only broadly defined and poorly understood [11]. Miyabayashi and Mundkur [16] roughly mapped Anatidae flyways at the species level in the East Asian-Australasian Flyway (EAAF) in 1999 (Figures 1, 2, and 3), but similar information is unavailable for many Anatidae species in the Central Asian Flyway (CAF). The EAAF supports more waterbird species than any other flyway in the world, but $>45 \%$ of the global human population lives within its boundaries [17], and numerous threats to waterbirds exist including habitat loss from agricultural

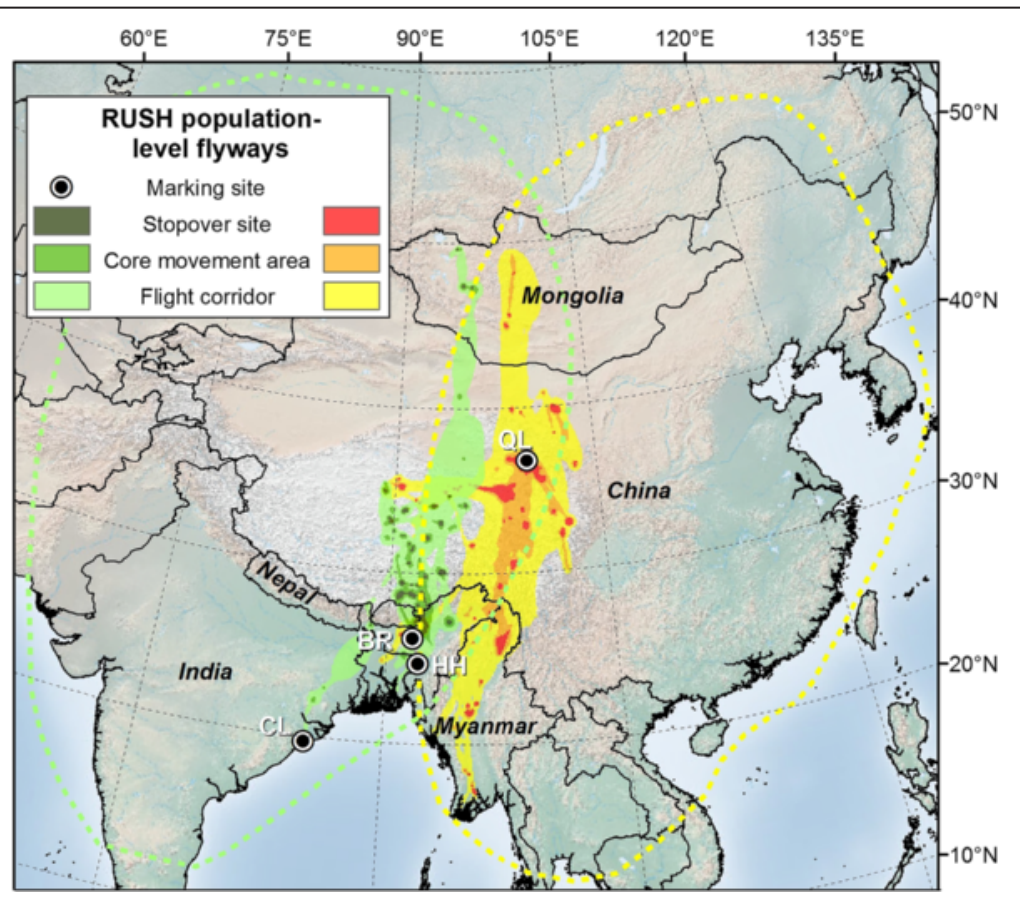

Figure 1 Estimated migration routes and relative use of ruddy shelducks (RUSH) by population in the CAF. Data groupings based on geographic proximity of marking sites. From darkest to lightest, colors represent 50\%, 75\% and 99\% cumulative probability contours. Marking sites include Qinghai Lake, China (QL), Brahmaputra River, India (BR), Hakaluki Haor, Bangladesh (HH) and Chilika Lake, India (CL). The western (green) route shows relative use for RUSH marked in northeast India and Bangladesh. The eastern (yellow-red) route shows relative use for RUSH marked at Qinghai Lake, China. Dotted lines represent the RUSH population-level range outlines depicted in Miyabayashi and Mundkur [16]. 


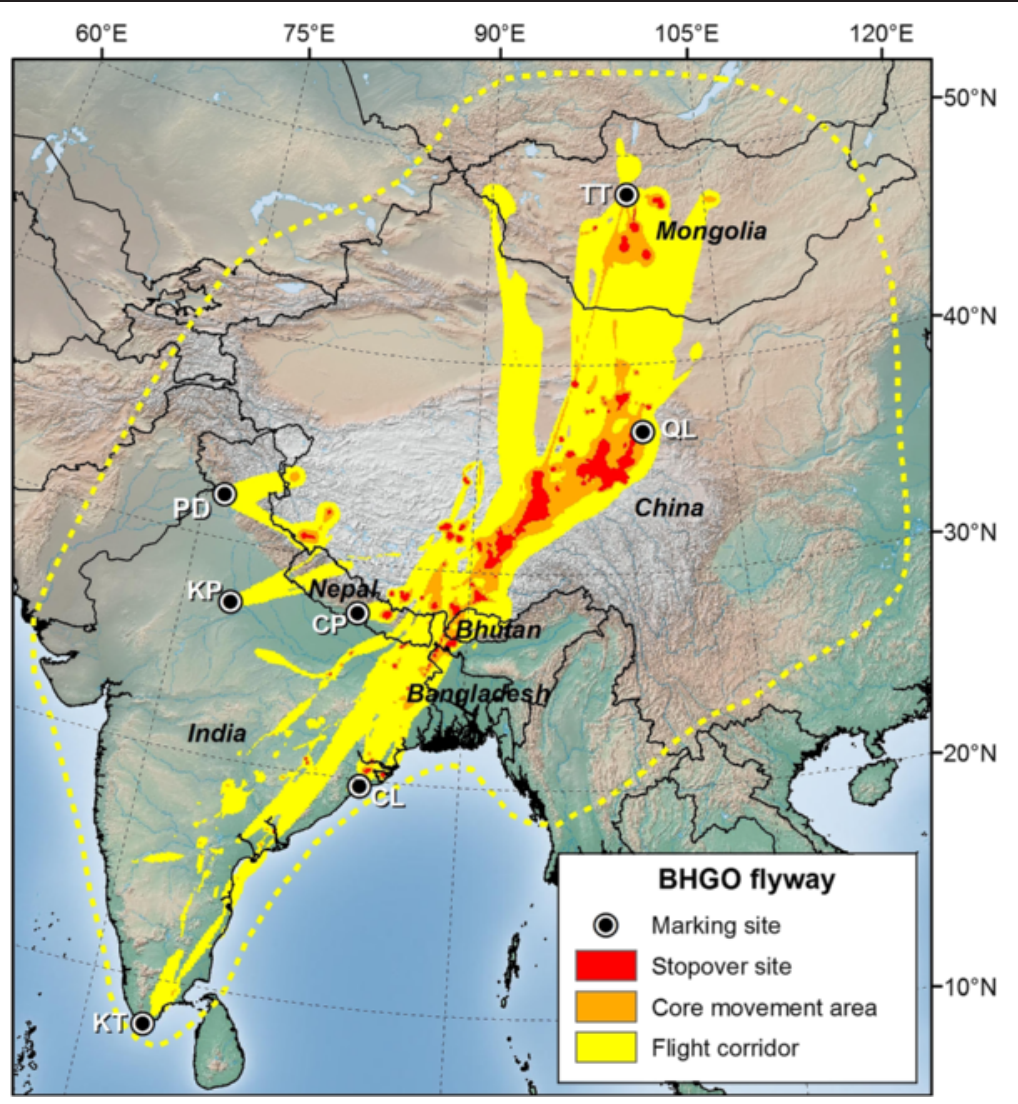

Figure 2 Estimated migration route and relative use of bar-headed geese (BHGO) in the CAF. From darkest to lightest, colors represent 50\%, 75\% and 99\% cumulative probability contours. Marking sites include Terkiin Tsagaan Lake, Mongolia (TT), Qinghai Lake, China (QL), Chitwan National Park, Nepal (CP), Pong Dam, India (PD), Keoladeo National Park, India (KP), Chilika Lake, India (CL) and Koonthankulam, India (KT). The dotted line represents the BHGO range outlines depicted in Miyabayashi and Mundkur [16].

activities and coastal development, pollution, and hunting [18]. As a result, the EAAF has the highest number of globally threatened waterbird species of any major flyway [17]. In an effort to promote conservation of waterbirds and their habitats in the CAF and EAAF, a flyway-wide coalition of governments and non-government organizations known as the Asia-Pacific Migratory Waterbird Conservation Strategy was established in 1996 [19].

Spatial representations of waterfowl flyways have improved markedly since Lincoln's first North American maps, but research has yet to incorporate data from satellite telemetry studies to quantitatively describe relative use within flyways. Even the most comprehensive spatial representations of waterfowl flyways are largely qualitative accounts, relying on data from a variety of sources which fail to fully capture connectivity, individual movement routes and relative use within flyways. For example, Bellrose [20,21] highlighted important migration corridors within North American waterfowl flyways by estimating the direction of passage and relative magnitude of birds migrating between different areas within flyways. Bellrose's maps were based primarily on band return data, which provide little information beyond a start and endpoint, and are inherently biased towards areas with high human population density and hunter activity. Other existing waterfowl flyway maps, such as those in Scott and Rose [22] and Miyabashi and Mundkur [16], are broadly outlined geographic boundaries that encompass a collection of data from a variety of sources, including population monitoring survey data, band return locations, re-sightings of color-marked individuals, and anecdotal accounts.

Beginning in 2006, the United Nations Food and Agriculture Organization (FAO) and the U.S. Geological Survey (USGS) developed a research partnership to assess waterfowl movements throughout Asia and apply models to evaluate their potential to transmit and spread disease. By the end of 2013, the USGS-FAO marking projects had deployed more than 550 satellite transmitters on 26 waterfowl species across 12 countries in Africa and Asia, with a majority in the CAF and EAAF [23].

Satellite and GPS (Global Positioning System) data from the FAO-USGS projects and other avian marking studies provide detailed route information that can improve our 


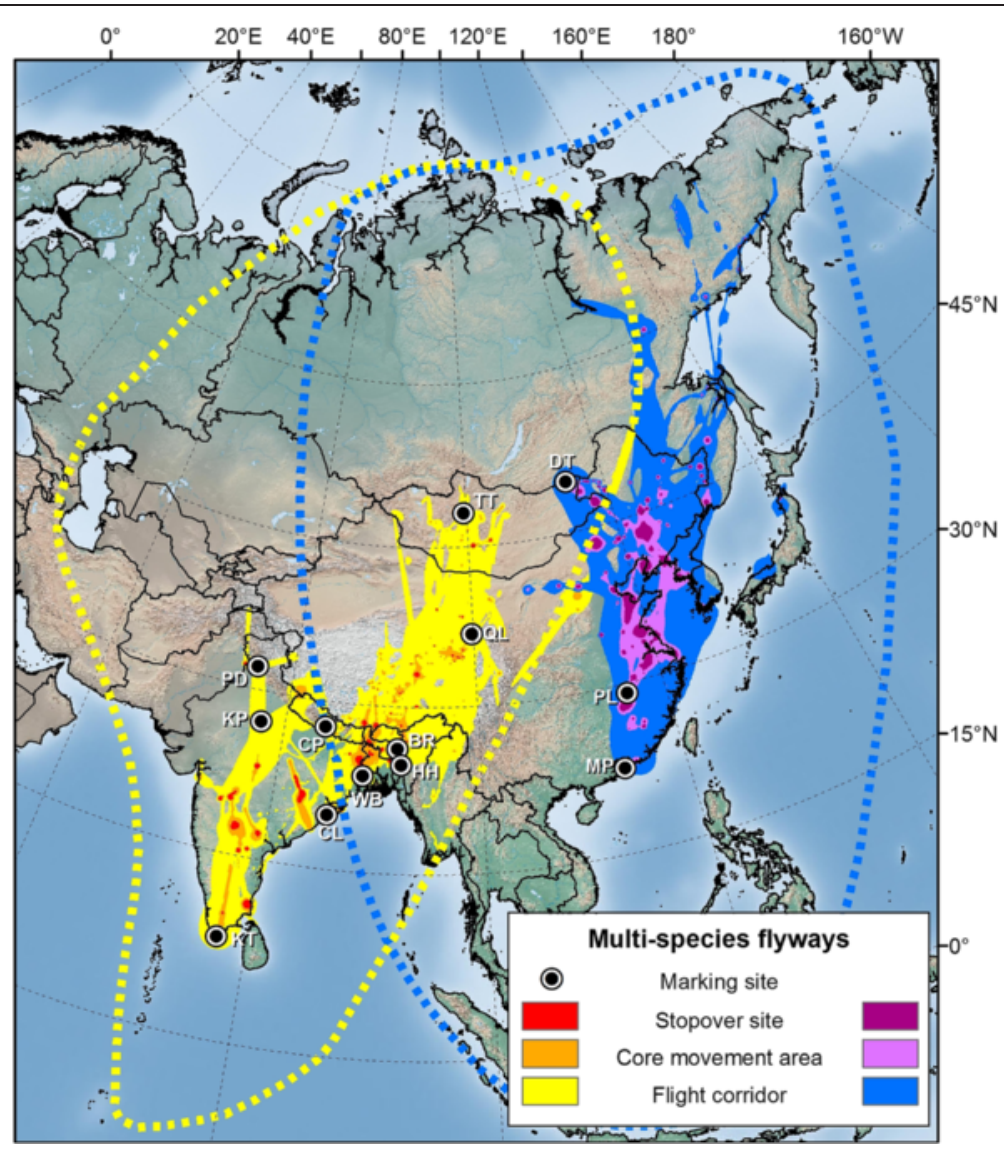

Figure 3 Estimated migration routes of Anatidae in the CAF and EAAF. Relative use for CAF displayed in yellow-red and relative use for EAAF displayed in blue-purple. From darkest to lightest, colors represent 50\%, 75\% and 99\% cumulative probability contours. CAF marking sites include Terkiin Tsagaan Lake, Mongolia (TT), Qinghai Lake, China (QL), Chitwan National Park, Nepal (CP), Pong Dam, India (PD), Keoladeo National Park, India (KP), Brahmaputra River, India (BR), Hakaluki Haor, Bangladesh (HH), West Bengal, India (WB), Chilika Lake, India (CL) and Koonthankulam, India (KT). EAAF marking sites include Mai Po, China (MP), Poyang Lake, China (PL) and Delger Tsagaan Lake, Mongolia (DT). Dotted lines represent CAF and EEAF flyway outlines depicted in Miyabayashi and Mundkur [16].

knowledge of flyway systems, including data on migration timing, connectivity between breeding and non-breeding areas, migration speed, stopover sites and route fidelity [24]. Researchers have used several methods - most notably, kernel density estimators - to estimate animal space use (i.e., home ranges) from GPS and satellite telemetry data, primarily in breeding and wintering areas. These methods estimate a utilization distribution (UD), which is a probability density representing an animal's relative frequency of occurrence in space and time $[25,26]$. However, traditional processes for estimating UDs do not account for temporal structure of observations and therefore perform very poorly for actively migrating animals [27].

For migratory species, the Brownian bridge movement model (BBMM) improved upon other methods by estimating a UD based on the animal's movement path, highlighting both movement corridors and stopover sites. This method calculates the probability of an animal's use in between telemetry locations by incorporating the distance and elapsed time between successive locations, the location error, and the Brownian motion variance, which estimates an animal's mobility based on its speed and direction of movement [27]. Sawyer et al. [28] used the BBMM method to estimate population-level migration routes of mule deer. Building on the BBMM, the dynamic BBMM ( $\mathrm{dBBMM})$ treats migration movements probabilistically and accounts for temporal autocorrelation in location data. However, instead of assigning a constant Brownian motion variance to all locations in a particular dataset, the $\mathrm{dBBMM}$ allows the parameter to vary along the movement path in response to changes in behavior (movement speed) during migration [29]. Specifically in birds, a dynamic variance parameter helps to more accurately distinguish between route segments that function as stopover sites and local movements versus those used primarily as flight corridors.

The objective of this paper is to examine how analyses of satellite and GPS movement data can improve our 
understanding of migratory bird flyways. We use a new approach to map flyways quantitatively, compare our results to existing range maps and flyway outlines, and present new information on migratory pathways provided by our movement models. Through the FAOUSGS marking program, we use dBBMMs and location data from 141 marked waterfowl to depict examples of probabilistic flyways at the population, species and multi-species levels in the CAF and EAAF. Our examples provide relative space use of bar-headed geese (Anser indicus), ruddy shelducks (Tadorna ferruginea), and nine other waterfowl species during their semiannual migrations.

\section{Results and discussion}

Our example maps show how the dBBMM can be applied to bird telemetry data to map migration routes and estimate relative use within flyways. Specifically, our results (1) provide evidence suggesting strong connectivity in two separate ruddy shelduck populations, (2) highlight heavily used stopover sites, areas of spatial overlap, and variable migration speeds in bar-headed goose routes, and (3) identify important stopover regions used by multiple species throughout parts of Asia.

\section{Population-level flyway}

Population-level UDs of ruddy shelducks $(n=31)$ showed relative use of two separate migration corridors within the CAF, likely representing two distinct populations that exhibit relatively strong connectivity between breeding and wintering areas (Figure 1; [24]). While all ruddy shelducks migrated along a north-northeast to south-southwest trajectory that bisected the Himalaya Cordillera, birds marked in Bangladesh and northeast India traveled through a corridor several hundred kilometers to the west of those marked at Qinghai Lake. The core use area for birds in the western population included several stopover sites in close proximity to and on both flanks of the Himalayan crest. Ruddy shelducks in the eastern population spent much of the migration period at stopover sites in the vicinity of Qinghai Lake and Madoi County, Tibet. North of the Qinghai-Tibetan Plateau, birds from both populations traveled largely without stops across the Gobi Desert en route to and from breeding grounds in Mongolia. Similarly, birds in the eastern population migrated with few stops from Madoi County south to wintering areas in Myanmar. Although our population-level routes for ruddy shelducks cover a smaller spatial extent than the range outlines found in Miyabayashi and Mundkur [16], our results corroborate their depiction of two separate populations (eastern and western) in the CAF based on census data from the late 1980s and 1990s (Figure 1).

\section{Single species flyway}

In contrast to ruddy shelducks, there was a high degree of spatial overlap among bar-headed goose populations. Our estimated UD aggregating data from 47 bar-headed geese marked at seven sites in the CAF clearly delineates key stopover sites within a heavily traveled migration corridor (Figure 2). Remote, high-elevation lakes along the eastern Qinghai-Tibetan Plateau received the most use and were visited by geese from four of the seven marking sites. The core area of use extended southwest from the Qinghai Lake region towards Lhasa, Tibet and southward to the northernmost extent of Bangladesh. Duration and distance of migration varied by marking site, as described in more detail in Takekawa et al. [30]. Notably, geese marked in the northern and southern limits (Terkhiin Tsagaan Lake, Mongolia, Chilika Lake, India and Koonthankulam, India) stopped more frequently and for longer durations while traveling through the core use area than they did when migrating through these margins. dBBMM UDs also emphasized the individual variation (or lack thereof) in migration paths used by these same birds throughout different parts of their journeys. While flying at the edge of their range, individual geese generally followed separate routes, but they funneled together into a relatively narrow corridor while traveling through the eastern Qinghai-Tibetan Plateau. Birds marked in Nepal and interior northern India bred in the southern Qinghai-Tibetan Plateau, migrating a relatively short distance without major stops. Fifty percent of bar-headed geese marked at Qinghai Lake, China underwent molt migration to an area separate from their breeding area, usually to the southeast. Our comparison of our map to the bar-headed goose range outlined from sightings in Miyabayashi and Mundkur [16] suggests that future marking efforts to the east and west could help provide a more complete picture of the overall flyway (Figure 2).

\section{Multi-species flyways}

Our example of a multi-species flyway map depicting Anatidae migrations in the CAF $(n=112)$ and EAAF $(n=29)$ suggests that the two flyways are spatially distinct and that many stopover areas are used by more than one species (Figure 3). Within the broad outlines depicted in Miyabayashi and Mundkur [16], our results serve as a first attempt to define flight corridors and stopover regions used by multiple species on which future studies can build. Only one bird, a northern shoveler (Anas clypeata) marked in Bangladesh that traveled $\sim 6,000 \mathrm{~km}$ to eastern Siberia, crossed over from the CAF to the EAAF. Because the majority (66\%) of birds in the EAAF (versus $23 \%$ in the CAF) analysis were marked with Argos satellite transmitters with larger temporal gaps between successive locations, model outputs in the EAAF showed a higher 
degree of uncertainty relative to CAF UDs. As a result of this uncertainty, many flight corridors depicted in this map encompass a larger geographic area than if they were derived solely from GPS data. While this uncertainty may have decreased our ability to pinpoint localized stopover sites in the EAAF, our results nonetheless provide valuable information on relative use and connectivity.

\section{Improving understanding of migratory flyways}

Using movement data and ABBMM UDs improves our understanding of migratory flyways by helping to fill many of the gaps in current flyway knowledge. Rather than drawing upon discrete data collection events such as population surveys, band returns and sightings, our flyway examples are based on individual movement paths and provide probabilistic estimates of space use by groups of migrating birds. On their own, satellite telemetry data offer improvements to traditional data types by providing information on timing, individual connectivity, and stopover sites. However, even among studies using satellite telemetry and GPS data, line segments connecting successive locations and/or minimum convex polygons remain the most common method to describe movements during periods of migration (e.g., [8,31,32]). Our probabilistic flyways have advantages over these approaches because they differentiate between areas used as stopover sites, areas that function as flight corridors, and areas that receive little or no use at all. By aggregating multiple UD outputs to create a flyway-wide map, we gain insight into patterns of relative use, timing and connectivity beyond the individual level.

\section{Considerations for applying the $\mathrm{dBBMM}$ approach}

The high costs of transmitters, deployment, and data access associated with satellite tracking studies make it difficult to obtain large sample sizes [24,33]. A sensitivity analysis of our data confirmed that our sample sizes are insufficient to be considered representative of entire realworld flyways. In the five separate datasets ( 2 populationlevel, 1 species level and 2 multi-species level) we used to create flyway maps, the average percent volume of intersection (\%VI) between subsamples of multi-individual UDs and the corresponding overall flyway UD did not reach an asymptote but steadily increased until we included the entire sample in the analysis (see Additional file 1: Figure S1). The curve depicting \%VI for ruddy shelducks in India and Bangladesh, where we only marked 8 individuals, had the steepest slope.

We recognize that small sample sizes are a drawback inherent in all satellite tracking studies and that relying on movement data from relatively few birds limits our ability to make strong inferences at the population level and beyond. However, the value in our approach lies in the new information it provides on migratory flyways, and we suggest that studies using dBBMM analyses help strengthen conclusions by supporting results with additional data such as surveys, stable isotopes, band returns, sightings, and genetics data. Alternatively, researchers may be able to overcome small sample sizes by directing marking efforts towards answering more focused questions at the population or species level, rather than deploying transmitters on multiple species across a large spatial extent [33].

\section{Implications for conservation and management}

dBBMM UDs can help inform conservation prioritization at a variety of spatial scales and demographic units, ranging from large-scale, multi-species flyways to more localized, detailed population-level routes. If the goal is to manage for overall waterfowl numbers and species diversity within a flyway, multi-species flyway maps help highlight the most cost-effective conservation options. dBBMM UDs can also identify the relative importance of different molting areas where large numbers of waterfowl aggregate during the post-breeding period and are thereby vulnerable to habitat degradation or anthropogenic disturbance [34]. On the other hand, single-species and population-level UDs help identify important habitats used by a particular species or demographically distinct populations, which could be useful for managing species or populations of special concern.

The multi-species flyway map of the CAF and EAAF highlights the eastern Qinghai-Tibetan Plateau and the Yellow Sea as primary migratory corridors containing important staging and stopover sites (Figure 3). Habitat alteration during recent decades in both of these areas is affecting waterfowl populations. In the Qinghai-Tibetan Plateau, agricultural development and changes to temperature and precipitation regimes may affect reproductive chronology and wintering distribution of waterfowl species [30]. In the Yellow Sea, rapid conversion of intertidal wetland habitat for land reclamation projects coupled with marked waterbird population declines throughout the region have led scientists to identify the area as a high conservation priority [18].

Output UDs from dBBMM analyses could be used to inform conservation in this area by incorporating a variety of spatial analyses involving waterfowl space use, including relationships with habitat types, climate conditions, and disease risk. For example, Takekawa et al. [7] used UDs from BBMM analyses to examine the spatial relationship between migration corridors of Anatidae and outbreaks of highly pathogenic avian influenza in the EAAF, while Byrne et al. [35] used dBBMM UDs to characterize habitat selection patterns in coyotes (Canis latrans), white-tailed deer (Odocoileus virginianus) and Rio Grande wild turkey (Meleagris gallopavo intermedia).

\section{Conclusions}

Empirical estimates of migratory flyways based on satellite tracking data help build upon largely qualitative 
accounts that have formed the basis of traditional flyway maps. Specifically, the dBBMM improves our understanding of flyways by estimating relative use throughout the flyway, providing detailed, quantitative information on migration timing and population connectivity, and accounting for uncertainty between observed locations. This new approach can be a valuable conservation tool because it goes beyond delineating spatial boundaries of migration routes and provides a more quantitative way to identify important movement corridors, staging and stopover sites, and demographically distinct populations. Conservation planners can use UD layers from dBBMMs in conjunction with other types of supporting data to help inform management decisions and incorporate these layers into various spatial analyses. While our approach offers many improvements over traditional methods for describing flyways, it will not replace these existing flyway data. Instead, dBBMM outputs fill many of the gaps in current flyway knowledge and help prioritize areas for future marking studies, surveys, and conservation efforts.

\section{Methods}

\section{Capture and Marking}

We marked birds at 10 sites in the CAF and three sites in the EAAF (Table 1; Figures 1, 2, 3). We captured birds using monofilament leg nooses, mistnets and net launchers. Upon capture, we placed birds in individual cloth bags and fitted them with Argos $(n=55)$ or ArgosGPS $(n=86)$ transmitters that were either solar $(n=138)$ or battery powered $(n=3)$. (Microwave Telemetry, Inc., Columbia, MD, USA). We secured solar powered transmitters to birds with a teflon ribbon harness (Bally Ribbon Mills, Bally, PA) and glued external, battery powered transmitters to plastic neck collars ( 2 on bar-headed geese in Keoladeo National Park, India and 1 on a bar-headed goose in Chitwan National Park, Nepal). Transmitters ranged from $9.5 \mathrm{~g}$ to $70 \mathrm{~g}$ (Table 1$)$ and average $( \pm \mathrm{SE}$ ) weights were 2.1 $\pm 0.1 \%$ of the bird's body mass prior to marking. After processing, we released birds near capture locations as soon as possible, usually within 1-4 hrs. We used capture, handling, and marking procedures approved by the USGS Patuxent Wildlife Research Center Animal Care and Use Committee.

\section{Assigning locations to annual cycle stage}

We used the complete sequence of locations that occurred between the breeding and wintering areas to estimate UDs for spring and fall migrations, only including migration events that spanned the entire distance between the two areas. Because we marked 11 different Anatidae species across a wide range of latitudes, there was considerable variation in migration phenology. We assigned locations to annual cycle stages (wintering, spring migration, breeding, fall migration) based on geographic area, scale of movement, arrival and departure dates, and comparisons of these metrics to those of conspecifics from the same marking site. Within and across marked species in our study, individual birds differed in their migration strategies. Consistent with many waterfowl species, some birds molted in close proximity to their breeding area, while others traveled hundreds of kilometers to separate wetlands [36].

\section{Data filtering and preparation}

We received telemetry data from the Argos satellite tracking system (CLS America Inc., Largo, MD, USA). The average time between consecutive Argos locations was $22.4 \pm 1.7 \mathrm{hr}$, while the average time between consecutive GPS locations was $4.5 \pm 1.9 \mathrm{hr}$. To improve accuracy of Argos data, we used the Douglas Argos-Filter Algorithm 'hybrid' filter designed to account for sedentary periods (staging) interspersed with rapid, directional movement (migration) [37]. We retained only the highest quality location in each hour for Argos satellite data, allowing us to truncate the timestamp at the nearest hour and minimize computation time of dBBMMs. We used published error estimates for Argos locations of free-ranging waterfowl (based on concurrent [ $<5 \mathrm{~min}$ ] GPS locations; [37]) to calculate mean error values for each Argos location class (3, 2, 1, 0, A, B, Z) for data filtered by the Douglas ArgosFilter Algorithm 'hybrid' filter. These mean error values ranged from $0.45 \mathrm{~km}$ (location class 3) to $7.92 \mathrm{~km}$ (location class B) and served as $\mathrm{dBBMM}$ parameter inputs. We used a location error of $23.5 \mathrm{~m}$ for GPS data [38].

\section{Use of dBBMMs}

We ran dBBMMs using the 'move' package [39] in Program $\mathrm{R}$ [40] to estimate one UD for each full migration event in our data. In a sequence of three locations, the dBBMM assumes constant movement between the first and third location, which are connected by a Brownian bridge, while the second location is treated as an independent observation. The $\mathrm{dBBMM}$ estimates $\sigma_{\mathrm{m}}^{2}$ for these three locations by maximizing the likelihood of observing the second location assuming random movement between successive locations and normally distributed location errors. The dBBMM identifies changes in movement speed and direction along the entire movement path and for user-defined subsets (windows) of locations, it calculates separate $\sigma_{\mathrm{m}}^{2}$ values that correspond to these different movement behaviors. Within a sliding window with $w$ locations, the $\mathrm{ABBMM}$ determines whether there is a behavioral change by comparing model fit using one or two estimates of $\sigma_{\mathrm{m}}^{2}$. Specifically, the model uses Bayesian Information Criterion values to compare the log-likelihood of using one $\sigma_{\mathrm{m}}^{2}$ value for the whole window with the loglikelihood of a window split into two parts at a breakpoint located anywhere within the window. Because $\sigma_{\mathrm{m}}^{2}$ 
Table 1 Satellite telemetry data breakdown by species, marking location and date

\begin{tabular}{|c|c|c|c|c|c|c|c|}
\hline Flyway & Species & Country & Marking site & Marking dates & Data type & $\begin{array}{l}\text { Transmitter } \\
\text { Weights (g) }\end{array}$ & $n$ \\
\hline \multirow[t]{23}{*}{ Central Asian } & $\mathrm{BHGO}$ & Mongolia & Terkhiin Tsagaan Lake & Jul '08, Jul '09 & GPS & 30 & 11 \\
\hline & & China & Qinghai Lake & Mar '07, Mar '08 & GPS & 45 & 16 \\
\hline & & Nepal & Chitwan National Park & Feb '05 & 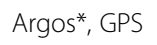 & 30,70 & $2^{a}$ \\
\hline & & India & Pong Dam & Mar'11 & GPS & 30 & $2^{a}$ \\
\hline & & India & Keoladeo National Park & Feb '05 & 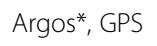 & 30,70 & $5^{a}$ \\
\hline & & India & Chilika Lake & Dec '08 & GPS & 30 & 6 \\
\hline & & India & Koonthankulam & Dec '08, Jan - Feb '09 & GPS & 30 & 5 \\
\hline & EUTE & India & Chilika Lake & Dec '08 & Argos & 9.5 & 1 \\
\hline & EUWI & India & West Bengal & Dec '09 & Argos & 12 & 3 \\
\hline & GADW & India & West Bengal & Dec '09 & Argos & 12 & 2 \\
\hline & GARG & Bangladesh & Hakaluki Haor & Mar '10, Mar '11 & Argos & 9.5 & $4^{b}$ \\
\hline & & India & West Bengal & Dec '09 - Feb '10 & Argos & 9.5 & $5^{\mathrm{b}}$ \\
\hline & & India & Chilika Lake & Dec '08 & Argos & 9.5 & 2 \\
\hline & & India & Koonthankulam & Dec '08 & Argos & 9.5 & 4 \\
\hline & NOPI & Bangladesh & Hakaluki Haor & Mar'11 & Argos & 9.5 & $3^{c}$ \\
\hline & & India & West Bengal & Jan '10 & Argos & 9.5 & $1^{c}$ \\
\hline & & India & Koonthankulam & Dec '08 & Argos & 12 & 2 \\
\hline & $\mathrm{NOSH}$ & Bangladesh & Hakaluki Haor & Mar '10, Mar '11 & Argos & $9.5,12$ & 5 \\
\hline & & India & Chilika Lake & Dec '08 & Argos & 12,18 & 2 \\
\hline & $\mathrm{RUSH}$ & China & Qinghai Lake & Sep '07, Mar '08, Sep '08 & GPS & 30,45 & 23 \\
\hline & & Bangladesh & Hakaluki Haor & Mar '10 & GPS & 22 & $5^{d}$ \\
\hline & & India & Brahmaputra River & Dec '09 & GPS & 22 & $2^{d}$ \\
\hline & & India & Chilika Lake & Dec '08 & GPS & 30 & $1^{d}$ \\
\hline \multirow[t]{7}{*}{ East Asian } & EUTE & China & Poyang Lake & Mar '07 & Argos & 12 & 3 \\
\hline & EUWI & China & Mai Po & Dec '08, Dec '09 & Argos, GPS & 12,22 & 5 \\
\hline & FATE & China & Poyang Lake & Mar '07 & Argos & 12,18 & 4 \\
\hline & GARG & China & Poyang Lake & Mar '07 & Argos & 12 & 1 \\
\hline & NOPI & China & Mai Po & Dec '08, Dec '09 & Argos, GPS & $12,18,22$ & 10 \\
\hline & SWGO & Mongolia & Delger Tsagaan Lake & Aug '06, Jul '08 & GPS & 30,70 & 4 \\
\hline & WHSW & Mongolia & Delger Tsagaan Lake & Aug '06 & GPS & 70 & 2 \\
\hline
\end{tabular}

Sample size refers to the number of birds included in the analyses. Species include bar-headed goose (BHGO), Eurasian teal (EUTE), Eurasian wigeon (EUWI), falcated teal (FATE), gadwall (GADW), garganey (GARG), northern shoveler (NOSH), northern pintail (NOPI), ruddy shelducks (RUSH), swan goose (SWGO), whistling swan (WHSW). Individual BHGO UDs from these three sites were grouped together in the single-species flyway. ${ }^{\mathrm{b}}$ Individual GARG UDs from these two sites were grouped together in the multi-species flyway. Individual NOPI UDs from these two sites were grouped together in the multi-species flyway. ${ }^{\mathrm{d}}$ Individual RUSH UDs from these three sites were grouped together in the population-level and multi-species flyways. *Battery powered, collar-mounted PTTs.

estimation requires at least three locations, the dBBMM requires a margin $(m)$ with a minimum of three locations at the start and end of each window in which no breakpoints can be estimated. Larger window sizes increase reliability in $\sigma_{\mathrm{m}}^{2}$ estimation but also increase the chance of missing short term changes in behavior. Larger margin sizes enhance the power to identify behavioral changes in the sliding window but increase the chance of missing breakpoints in the margin [29].

We calculated all UD output grids for GPS and Argos birds at the same spatial extent and at a $10 \mathrm{~km}^{2}$ grid resolution. We used a window size of 31 locations and margins of 11 locations for both GPS and Argos satellite data in all analyses based on Kranstauber et al. [29] and visual inspection of example results from our own data. This corresponded to a window length of approximately six days for GPS data and 28 days for Argos data.

\section{Creating individual-level routes from multiple migration events}

For birds with multiple full migration events recorded $(n=$ 41 ), we summed UDs from individual migration events to 
create migration routes that estimated relative use at the individual level throughout the entire year. The duration of migration events varied widely (range: $<24 \mathrm{hr}-184 \mathrm{~d}$ ) by individual, species, and marking site. To account for this variation when summing multiple UDs, we weighted each individual UD by its migration event duration, multiplying all pixel values in a UD by the total number of days elapsed during its associated migration event. We summed the pixel values of all their weighted UDs, and then re-scaled their cumulative pixel values to sum to 1 . The resulting UD represented the proportional amount of time occupied for each pixel across that bird's entire migration route based on movement data from all available seasons [28]. For birds that molted in a site separate from their breeding area, we included locations representing post-breeding movements as part of the fall migration event but excluded locations from molting period itself.

\section{Creating routes at the population, species and multi-species levels}

We used this same time-weighting and re-scaling procedure to produce population-level migration routes from individual routes, weighting individual bird UDs by migration event duration, summing these weighted UDs and re-scaling the cumulative pixel values for the resulting population-level UD. We grouped individuals into populations based on geographic proximity of marking sites (Table 1). Population-level UDs represent an estimate of the relative use during migration for each pixel across all marked birds in the population. We weighted each population-level UD by its average migration event duration, summed these weighted population UDs and re-scaled the resulting surface to estimate a singlespecies flyway route. Finally, we time-weighted and summed single-species routes to create multi-species migration routes for the CAF and EAAF. Because birds with multiple full migration events recorded showed fidelity to migration corridors across seasons and years, we did not calculate UDs for separate seasons at the population, species or multi-species level.

We calculated cumulative probability contours for each UD at the population, species and multi-species level to display migration routes on a map. We assumed UD values within the $50 \%$ contour were stopover sites used for resting and feeding over multiple days, those between the $50 \%$ and $75 \%$ contours were core movement areas characterized by short flights and frequent stops, and those between the $75 \%$ and $99 \%$ contours were flight corridors with minimal stops.

\section{Sensitivity analysis}

We ran a sensitivity analysis in Program $\mathrm{R}$ that estimated the degree to which our samples of marked birds were representative of real-world flyways. For each subsample of $k$ marked birds chosen from the total sample size of $n$ marked birds (starting at $k=1$ and continuing to $k=n$ in increments of 3 ), we calculated the average $\%$ VI between (1) each of the volumes of multi-individual UDs constructed from a random sample (up to 100) of all possible combinations of $k$ individuals, and (2) the volume of the overall flyway UD constructed from $n$ marked birds in a flyway. We then fitted a smoothed curve to the data using a locally weighted regression (LOESS; [41]). If the final aggregated UDs depicted in Figures 1, 2 and 3 were accurate representations of realworld flyways, the curves would asymptote near $100 \%$ VI before reaching $100 \%$ of $n$.

\section{Additional file}

Additional file 1: Figure S1. Percent volume of intersection between subsamples of aggregated individual UDs and overall flyway UDs.

Individual curves correspond to two population-level ruddy shelduck routes, one species-level bar-headed goose route, and two multi-species routes (Central Asian and East Asian-Australasian Flyways).

\section{Competing interests}

The authors declare that they have no competing interests.

\section{Authors' contributions}

ECP, DJP, and JYT wrote the manuscript. SHN, DJP and JYT conceived and designed the experiments. ECP, SHN, DJP, XMX, LZ, NB, SB performed the experiments: ECP, DJP, and JYT analyzed the data. ECP, SHN, DJP, XMX, LZ, $\mathrm{NB}, \mathrm{SB}$, and JYT contributed materials and analysis tools. All authors read and approved the final manuscript.

\section{Acknowledgements}

The authors thank United Nations FAO, USGS, and NSF (SGER 0713027) for funding this program. We are grateful to the local field staff and national and local agencies of China, Mongolia, India, and Bangladesh for local field support and permissions granted for this work. We are grateful to the research partners, local field staff and national and local agencies of China (B. Yan, Z. Xing, Y. Hou, P. Leader, B. Smith, K. Spragens), Mongolia (T. Natsagdorj, P. Butler, C. Bishop, L. Hawkes, M. Wikelski), India (A. George, S. Rao, P. Sathiyaselvam, P. Gangaiamaran, S. Heath, T. Mundkur, L. Hawkes, T. McCracken), Nepal (R. Suwal), and Bangladesh (S. Saif, S. Mohsanin, P. Hosseini, K. Vandegrift, A. Mikolon, A. Islam, P. Daszak, N. Hill) for local field support and permissions granted for this work. We thank Kamran Safi, Dan Esler, and two anonymous reviewers for improving earlier versions of this manuscript. Finally, we thank Max Czapanskiy and Julie Yee of the USGS for their assistance with statistical analyses. The use of trade, product, or firm names in this publication is for descriptive purposes only and does not imply endorsement by the U.S. Government. The views expressed in this information product are those of the author(s) and do not necessarily reflect the views or policies of FAO.

\section{Author details}

${ }^{1}$ U.S. Geological Survey, Patuxent Wildlife Research Center, Beltsville, MD 20705, USA. ${ }^{2}$ Food and Agriculture Organization of the United Nations, Emergency Center for Transboundary Animal Disease, Hanoi, Vietnam. ${ }^{3}$ Department of Botany and Microbiology, Center for Spatial Analysis, University of Oklahoma, Norman, OK 73019, USA. ${ }^{4}$ Institute of Biodiversity Science, Fudan University, Shanghai 200433, China. ${ }^{5}$ Computer Network Information Center (CNIC), Chinese Academy of Sciences, Beijing 100080, China. ${ }^{6}$ Wildlife Science and Conservation Center, Ulaanbaatar 210351, Mongolia. ${ }^{7}$ Bombay Natural History Society, Hornbill House, Mumbai 400 001, India. ${ }^{8}$ U.S. Geological Survey, Western Ecological Research Center, San Francisco Bay Estuary Field Station, Vallejo, CA 94592, USA. ${ }^{9}$ National Audubon Society, Science Division, 220 Montgomery Street, San Francisco, CA 94104, USA. 
Received: 16 October 2014 Accepted: 6 January 2015

Published online: 02 February 2015

\section{References}

1. Hutto RL. On the importance of en route periods to the conservation of migratory landbirds. Stud Avian Biol. 2000;20:109-14.

2. Faaborg J, Holmes RT, Anders AD, Bildstein KL, Dugger KM, Gauthreaux SA et al. Recent advances in understanding migration systems of New World land birds. Ecol Monogr. 2010;80:3-48.

3. Newton I. The Migration Ecology of Birds. San Francisco, CA: Academic Press; 2008.

4. Sillett TS, Holmes RT. Variation in survivorship of a migratory songbird throughout its annual cycle. J Anim Ecol. 2002;71:296-308.

5. Bonter DN, Gauthreaux SA, Donovan TM. Characteristics of important stopover locations for migrating birds: Remote sensing with radar in the Great Lakes Basin. Conserv Biol. 2009;23:440-8.

6. Klaassen $\mathrm{RH}$, Hake M, Strandberg R, Koks BJ, Trierweiler C, Exo K-M, et al. When and where does mortality occur in migratory birds? Direct evidence from long-term satellite tracking of raptors. J Anim Ecol. 2014;83:176-84.

7. Takekawa JY, Newman SH, Xiao XM, Prosser DJ, Spragens KA, Palm EC, et al. Migration of waterfowl in the East Asian Flyway and spatial relationship to HPAI H5N1 outbreaks. Avian Dis. 2010;54(1 Suppl):466-76.

8. Bengtsson D, Avril A, Gunnarsson G, Elmberg J, Söderquist P, Norevik G, et al. Movements, Home-Range Size and Habitat Selection of Mallards during Autumn Migration. PloS One. 2014;9:e100764.

9. De La Cruz SEW, Eadie JM, Miles AK, Yee J, Spragens KA, Palm EC, et al. Resource selection and space use by sea ducks during the non-breeding season: Implications for habitat conservation planning in urbanized estuaries. Biol Cons. 2014;169:68-78.

10. Mack GG, Clark RG. Home-range characteristics, age, body size, and breeding performance of female mallards (Anas platyrhynchos). Auk. 2006;123:467-74.

11. Boere GC, Stroud DA. The flyway concept: what it is and what it isn't. In: Boere GC, Galbraith CA, Stroud DA, editors. Waterbirds Around the World. Edinburgh, UK: The Stationery Office; 2006. p. 40-7

12. Hochbaum HA. Travels and Traditions of Waterfowl. Minneapolis, MN: University of Minnesota Press; 1955.

13. Lincoln FC. The Waterfowl Flyways of North America. Washington, D.C.: U.S: Department of Agriculture Circular; 1935. p. 342.

14. Hawkins AS, Hanson RC, Nelson HK, Reeves HM. Flyways: Pioneering Waterfowl Management in North America. Washington, D.C.: US Fish and Wildlife Service; 1984.

15. Isakov YA. Proceedings of the Second European Meeting on Wildfowl Conservation: 9-14 May 1966. In: Salverda Z, editor. Proceedings of the Second European Meeting on Wildfowl Conservation: 9-14 May 1966; Noordwijk aan Zee, The Netherlands. The Netherlands: Ministry of Cultural Affairs, Recreation and Social Welfare; 1967. p. 125-38.

16. Miyabayashi Y, Mundkur T: Atlas of Key Sites for Anatidae in the East Asian Flyway. Kuala Lumpur, Malaysia: Wetlands International; 1999. http://www. jawgp.org/anet/aaa1999/aaaendx.htm.

17. Barter MA: Shorebirds of the Yellow Sea: Importance, threats and conservation status. Canberra, Australia: Wetlands International; 2002. http://www.wetlands. org/Portals/0/publications/Book/WI ShorebirdsYellowSea_2002.pdf.

18. Kirby JS, Stattersfield AJ, Butchart SHM, Evans MI, Grimmett RFA, Jones VR, et al. Key conservation issues for migratory land and waterbird species on the world's major flyways. Bird Life Int. 2008;18:S49-73.

19. Asia-Pacific Migratory Waterbird Conservation Committee. Asia-Pacific Migratory Waterbird Conservation Strategy: 2001-2005. Kuala Lumpur, Malaysia: Wetlands International - Asia Pacific; 2001.

20. Bellrose FC. Ducks, Geese, and Swans of North America. Harrisburg, PA: Stackpole Books; 1976.

21. Bellrose FC: Waterfowl migration corridors east of the Rocky Mountains in the United States. Illinois Natural History Survey Biology Notes 61. 1968.

22. Scott DA, Rose PM: Atlas of Anatidae populations in Africa and Western Eurasia. Wetlands International Publication 1996, 41. http://www.wetlands. org/WatchRead/Currentpublications/tabid/56/mod/1570/articleType/ download/articleld/1604/Default.aspx.

23. FAO-USGS Avian Influenza Projects. http://www.werc.usgs.gov/ ResearchTopicPage.aspx?id=17.

24. Webster MS, Marra PP, Haig SM, Bensch S, Holmes RT. Links between worlds: unraveling migratory connectivity. Trends Ecol Evol. 2002;17:76-83.
25. van Winkle W. Comparison of several probabilistic home-range models. J Wildl Manage. 1975;39:118-23.

26. Keating KA, Cherry S. Modeling utilization distributions in space and time. Ecology. 2009;90:1971-80.

27. Horne JS, Garton EO, Krone SM, Lewis JS. Analyzing animal movements using Brownian bridges. Ecology. 2007;88:2354-63.

28. Sawyer H, Kauffman MJ, Nielson RM, Horne JS. Identifying and prioritizing ungulate migration routes for landscape-level conservation. Ecol Appl. 2009;19:2016-25

29. Kranstauber B, Kays R, LaPoint SD, Wikelski M, Safi K. A dynamic Brownian bridge movement model to estimate utilization distributions for heterogeneous animal movement. J Anim Ecol. 2012;81:738-46.

30. Takekawa JY, Heath SR, Douglas DC, Perry WM, Javed S, Newman SH, et al Geographic variation in Bar-headed Geese Anser indicus: Connectivity of wintering areas and breeding grounds across a broad front. Wildfowl. 2009:59:100-23.

31. Vardanis $Y$, Klaassen RHG, Strandberg R, Alerstam T. Individuality in bird migration: routes and timing. Biol Lett. 2011;7:502-5.

32. Trierweiler C, Klaassen $\mathrm{RH}$, Drent $\mathrm{RH}$, Exo KM, Komdeur J, Bairlein F, et al. Migratory connectivity and population-specific migration routes in a long-distance migratory bird. Proc R Soc B. 2014;281:20132897.

33. Lindberg MS, Walker J. Satellite Telemetry in Avian Research and Management: Sample Size Considerations. J Wildl Manage. 2007;71:1002-9.

34. Hogan D, Thompson JE, Esler D. Survival of Barrow's goldeneyes during remigial molt and fall staging. J Wildl Manage. 2013;77:701-6.

35. Byrne ME, Clint McCoy J, Hinton JW, Chamberlain MJ, Collier BA. Using dynamic Brownian bridge movement modelling to measure temporal patterns of habitat selection. J Anim Ecol. 2014;83:1234-43.

36. Jehl Jr JR. Aspects of the molt migration. In: Gwinner E, editor. Bird Migration: Physiology and Ecophysiology. Berlin, Germany: Springer; 1990. p. 102-13.

37. Douglas DC, Weinzierl R, Davidson SC, Kays R, Wikelski M, Bohrer G. Moderating Argos location errors in animal tracking data. Methods Ecol Evol. 2012;3:999-1007.

38. Frair JL, Fieberg J, Hebblewhite M, Cagnacci F, DeCesare NJ, Pedrotti L. Resolving issues of imprecise and habitat-biased locations in ecological analyses using GPS telemetry data. Phil Trans R Soc B. 2010;365:2187-200.

39. Kranstauber B, Smolla M: move: Visualizing and analyzing animal track data. R package version 1.2.475. [http://cran.R-project.org/package=move] 2014.

40. R Core Team: R: A language and environment for statistical computing. Vienna, Austria: R Foundation for Statistical Computing; 2014. [http://www.R-project.org]

41. Trexler JC, Travis J. Nontraditional regression analyses. Ecology. 1993;74:1629-37.

\section{Submit your next manuscript to BioMed Central and take full advantage of:}

- Convenient online submission

- Thorough peer review

- No space constraints or color figure charges

- Immediate publication on acceptance

- Inclusion in PubMed, CAS, Scopus and Google Scholar

- Research which is freely available for redistribution

Submit your manuscript at www.biomedcentral.com/submit 